\title{
THE SIGNIFICANCE OF INTIMAL THICKENING IN THE ARTERIES OF THE NEWBORN
}

BY

\author{
J. H. ROBERTSON \\ From the Department of Pathology, University College Hospital, Ibadan, Nigeria
}

(RECEIVED FOR PUBLICATION APRIL 25, 1960)

From both Europe and North America there have been a number of reports describing the presence of cushion-like areas of intimal thickening and elastic reduplication in the arteries of foetuses and infants (Dock, 1946; Fangman and Hellwig, 1947; Levene, 1956; Robertson, 1960a). The significance of these intimal cushions is uncertain. They are believed by some to be pathological in nature and the early lesions of atherosclerosis. Another view regards them as being a physiological adaptation of the vessel wall to mechanical stress and as having little influence in dictating the later development of atherosclerosis.

At Ibadan, coronary occlusion is rarely seen in the adult African and in the literature there are many reports indicating that atherosclerosis, certainly of the aorta and coronary arteries, is much less severe and extensive in the African Bantu and Negro than in Europeans (Davies, 1948; Edington, 1954; Hannah, 1958; and others). The present investigation sets out to determine whether intimal thickenings occur in the arteries of the African newborn and to compare their incidence with that found in European and North American subjects.

\section{Methods}

The popliteal artery of one leg was examined in 52 newborn African infants, 32 of whom were male and 20 female. Their ages ranged from foetuses of 30 weeks gestation to babies 2 weeks old. Most, however, were full-term stillbirths. In 30 of the cases, 19 male and 11 female, the proximal parts of the anterior descending and circumflex branches of the left coronary artery were also examined. From each vessel a small segment was taken and after fixation in formalin, paraffin sections were prepared and stained by haematoxylin and eosin and Weigert's elastic tissue stain counter-stained by van Gieson.

\section{Findings}

In the newborn the intima of the muscular arteries consists of an elastic membrane, the internal elastic lamina, which is covered by the endothelium. The circular muscle of the media surrounds the intima and is bounded on its outer aspect by the adventitia. Of the 52 popliteal arteries examined, 42 (27 male and 15 female) showed areas in which there was a disturbance of this architecture. The pattern of this varied, but in most instances both the intima and media were affected to form a local cushion-like thickening of the wall. In the intima there occurred a reduplication of the internal elastic lamina so that several ccarse lamellae or sometimes numerous fine elastic filaments were formed between which smooth muscle cells could be seen (Fig. 1). In the underlying media bundles of longitudinally orientated muscle also contributed to the thickening

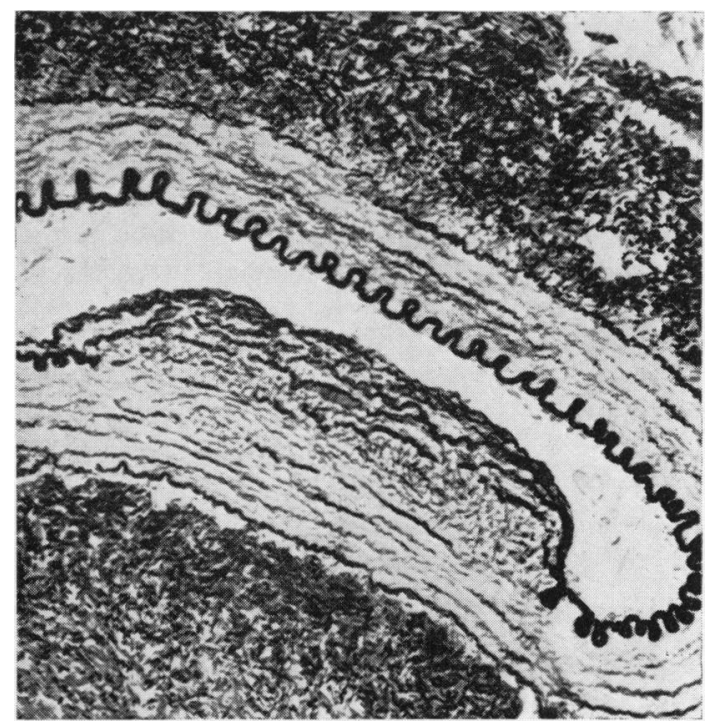

Fig. 1.-Popliteal artery. Full term stillbirth. A cushion-like thickening of the wall is present over which there is reduplication of the internal elastica. (Weigert $\times 150$.) 


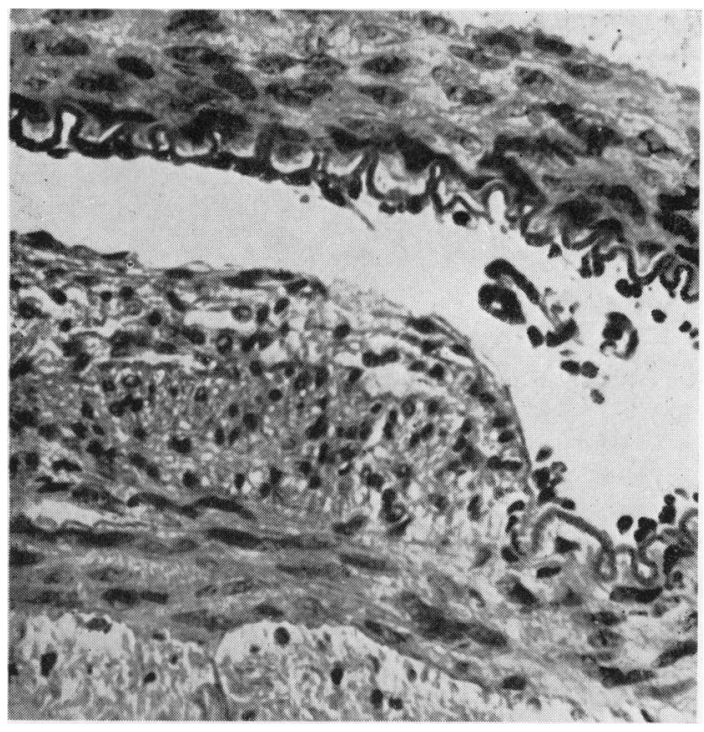

Fig. 2.-High power field of the cushion illustrated in Fig. 1. A band of longitudinal muscle is present in the media beneath the split elastica. (H. and E. $\times 300$.)

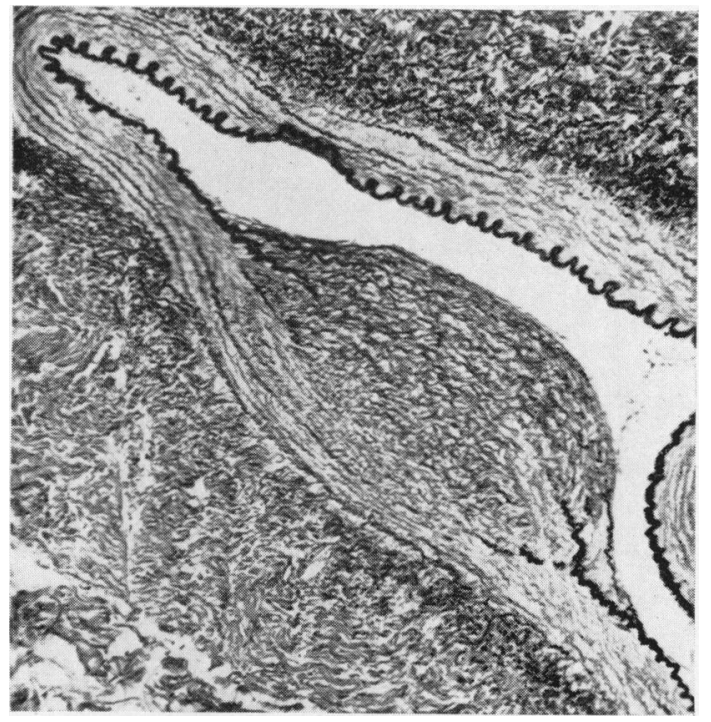

Fig. 3.-Popliteal artery. Full term stillbirth. A cushion showing marked reduplication of the internal elastica. The interstices of the elastic mesh contain many longitudinally orientated muscle cells. (Weigert $\times 86$.)

of the wall (Fig. 2). These longitudinal muscle bundles were the most conspicuous feature of many cushions and in some instances they formed the whole of the thickening, there being no reduplication of the internal elastica. Both the size and complexity of the cushions varied widely, ranging from small nodes of longitudinal muscle in the media to the formation of large musculo-elastic mounds (Fig. 3). They occurred especially at the margins and opposite the mouths of branches, but were apparently not restricted to these sites, although serial sections would have been required to confirm this.

The left coronary artery was examined in 30 subjects and in 16 of these (11 male and five female) cushion-like thickenings of the wall similar to those of the popliteal artery were found. In the coronary vessels reduplication of the internal elastica tended to be more prominent than bundles of longitudinal medial muscle in the formation of the cushions. Only very occasionally, however, did a thickening show no evidence of a medial component. In both the coronary and popliteal vessels the van Gieson stain revealed strands of fibrous tissue in some of the cushions. It was generally associated with the elastic fibrils of the intima. In no instance was it present in large amount and many cushions showed no evidence of a fibrous component.

\section{Discussion}

Two views exist as to the significance of intimal thickenings in the vessels of the newborn. Fangman and Hellwig (1947) and Levene (1956) considered those in the coronary arteries to be pathological and the earliest lesions of atherosclerosis. Dock (1946) and Robertson (1960a) on the other hand, believed that they represented a response of the vessel wall to mechanical stress. In the coronary vessels Dock attributed this stress to the changing length to which these vessels had to adapt themselves during cardiac systole. Robertson, however, described similar thickenings in the popliteal and brachial arteries of the foetus and considered that their function was to buffer a stress due to tugging at the margins of branches and other points of fixation of the vessel during its elongation with pulsation. It was believed that the presence of intimal cushions was of no significance in determining the later development of atherosclerosis, although, if the disease did occur, it tended to localize in these regions of stress (Robertson, 1960b).

In the present study of newborn African subjects, cushion-like thickenings were found in the popliteal and coronary arteries of 81 and $53 \%$ of cases respectively. In both vessels the incidence was slightly higher in males than females. From these findings it appears that intimal thickenings occur just as frequently in the newborn of the African Negro as in those of the white races. Thus, 
in a series of European foetuses, exactly similar structural changes were found in the popliteal artery of $76 \%$ of subjects (Robertson, 1960a) while, in North America, Fangman and Hellwig found coronary thickenings in $12(40 \%)$ of 30 newborn infants, the incidence being higher in males than females. Despite the similar findings in the newborn of both races, most authors are agreed that atherosclerosis is less marked in the African Bantu and Negro than in Europeans. Higginson and Pepler (1954), for example, have found that only $3 \%$ of African compared with $32 \%$ of Danish subjects of the fourth decade have severe coronary and aortic lesions. The results of the present study therefore support the view that the presence of intimal cushions in the vessels of the newborn plays little part in determining the later development of atherosclerosis.

\section{Summary}

The presence of areas of intimal thickening and elastic reduplication in the popliteal and coronary arteries of newborn African infants is described.
Their incidence was found to be similar to that in the newborn of European and North American subjects. The significance of these thickenings in the pathogenesis of atherosclerosis is briefly discussed.

I wish to thank Professor G. M. Edington for his advice and encouragement during the course of this work.

\section{REFERENCES}

Davies, J. N. P. (1948). Pathology of Central African natives. Mulago Hospital Post Mortem Studies IX Cardio-vascular Mulago Hospital Post Mortem

Dock, W.(1946). The predilection of atherosclerosis for the coronary arteries. J. Amer. med. Ass., 131, 875.

Edington, G. M. (1954). Cardiovascular disease as a cause of death in the Gold Coast African. Trans. roy. Soc. trop. Med. Hyg., $48,419$.

Fangman, R. J. and Hellwig, C. A. (1947). Histology of coronary arteries in newborn infants. Amer. J. Path., 23,901.

Hannah, J. B. (1958). Civilisation, race and coronary atheroma with particular reference to its incidence and severity in copperbelt Africans. Cent. Afr. J. Med., 4, 1.

Higginson, J. and Pepler, W. J. (1954). Fat intake, serum cholesterol concentration, and atherosclerosis in the South African Bantu; Part II. Atheroscler
Invest., 33, 1366.

Levene, C. I. (1956). The early lesions of atheroma in the coronary arteries. J. Path. Bact., 72, 79.

Robertson, J. H. (1960a). Stress zones in foetal arteries. J. clin. Path., 13, 133.

(1960b). The influence of mechanical factors on the structure of the peripheral arteries and the localization of atherosclerosis. Ibid., 13, 199. 